\title{
ANALISIS PELAKSANAAN FUNGSI PENGAWASAN INSPEKTORAT TERHADAP PENYELENGGARAAN PEMERINTAHAN PROVINSI PAPUA
}

\author{
Penulis: \\ Suparmi ${ }^{1}$ \\ suparmi.mkd@gmail..com
}

\begin{abstract}
This study aims to obtain a clear picture of the effects of supervision which consists of routine supervision, individual supervision, and monitoring of the administration of Papua Province. The type of data used is qualitative data and quantitative data. Primary and secondary data is the source of the data used. Data collection techniques used are field data and literature study data. The study was conducted using qualitative analysis techniques and quantitative analysis consisting of research instrument tests, standard assumption tests, and multiple regression analysis. The results showed that the routine supervision variable partially had a significant influence on the administration of the Papua Province. While the special supervision and partial monitoring variables do not have a significant effect on the administration of the Papua Province. Variables of routine supervision, individual supervision, and simultaneous monitoring have a significant influence on the administration of Papua Province. The routine supervision variable is the most dominant factor influencing the administration of Papua Province.
\end{abstract}

Keywords: Routine Oversight, Special Oversight, Monitoring, and Government Administration

\section{PENDAHULUAN}

Untuk meningkatkan efisiensi dan efektifitas pelaksanaan pemerintahan daerah bagi masyarakat, maka dibutuhkan partisipasi semua pihak terutama dari aparat yang akan melaksanakan pemerintahan. Pemerintahan yang efektif adalah kebutuhan yang sangat mendesak, terutama di era reformasi saat ini. Arah pendekatan ini berfokus pada penyediaan layanan kepada masyarakat dan sebagai upaya untuk menyampaikan kebijakan pemerintah pusat dan pada saat yang sama melaksanakan program pemerintah. Hal ini ditandai dengan adanya tuntutan masyarakat yang akan menunjang terciptanya aparatur pemerintahan yang bersih dan berwibawa, tertib dan teratur dalam menjalankan tugas dan fungsinya sesuai dengan peraturan yang berlaku. Tuntutan ini muncul karena adanya alasan bahwa terdapat praktik-praktik tidak terpuji yang dilakukan oleh pejabat pemerintah pada umumnya dan aparat

\footnotetext{
1 Pegawai Inspektorat Provinsi Papua
} 
pemerintah daerah pada khususnya. Salah satu penyebab terjadinya penyimpangan di kalangan aparat Pemerintah Daerah karena kurang efektifnya pelaksanaan pengawasan yang dilakukan oleh Badan yang ada dalam Pemerintahan itu.

Dalam membiayai pelaksanakan pembangunan daerahnya, Pemerintah Daerah membutuhkan dana yang cukup besar, baik itu pembiayaan rutin maupun pembiayaan pembangunan. Untuk itu perlu di gali potensi sumber pendapatan daerah yang merupakan sumber utama pembiayaan pembangunan. Dalam pelaksanaan Pemerintahan daerah tidak lepas dari system pengawasan. Pengawasan merupakan bagian penting dalam proses penyelenggaraan pemerintahan karena tanpa adanya fungsi kontrol, kekuasaan dalam suatu negara akan berjalan sesuai kehendak dan interprestasi pemegang kekuasaan (power maker). Oleh sebab itu dalam mewujudkan tujuan pembangunan di daerah, terutama dengan diberlakukannya Undang-Undang Nomor 23 Tahun 2014 (UU No 9/2015) tentang Pemerintahan Daerah maka pemerintah daerah harus mampu mengurus rumah tangganya, sebagai akibat penyelenggaraan otonomi daerah terutama pemanfaatan berbagai potensi perlu ditunjang dengan pengawasan yang baik.

Hal ini dimaksudkan agar penyelenggaraan pemerintahan daerah sesuai dan seirama dengan kebijakan pembangunan nasional yakni diarahkan untuk mengembangkan daerah dan menyelaraskan pertumbuhan antar daerah, antar kota dan desa serta antar bidang dan sektor, yang pada akhirnya dapat mengurangi terjadinya korupsi, kolusi dan nepotisme (KKN). Mencegah serta mengurangi terjadinya $\mathrm{KKN}$ adalah dengan cara menggerakkan roda pemerintahan di daerah serta memanfaatan potensi yang tersedia dengan melakukan tingkat pengawasan yang efektif dan efisien.

Harmawan (2012) dalam penelitiannya yang berjudul analisis fungsi pelaksanaan inspektorat Kabupaten Pangkajene memberikan hasil bahwa pelaksanaan system pengawasan yang dilihat dari segi pemeriksaan, pengujian dan pengusutan sudah berjalan dengan efektif. Hal ini dapat dilihat dari segi ketepatan waktu dalam melakukan pengawasan, serta keakuratan data 
yang dilaporkan Inspektorat Kabupaten Pangkajene dan Kepulauan. Siradja (2016) dalam penelitiannya dengan judul analisis pelaksanaan pengawasan Inspektorat Daerah terhadap kinerja Badan Kepegawaian Daerah Kota BauBau memberikan hasil bahwa penyusunan pengawasan yang dilakukan oleh pejabat inspektorat sudah cukup efektif dan seusia dengan SOP yang berlaku, pelaksanaan pengawasan yang dilakukan pejabat Inspektorat belum efektif, dan pelaksanaan penyusunan dan pertanggungjawaban laporan hasil pengawasan dari SKPD yang diperiksa yakni BPK belum ditunjang oleh ketersediaan data yang akurat/valid.

Berangkat dari uraian masalah diatas, maka penelitian ini bertujuan untuk menguji dan menganalisis pengaruh pengawasan rutin, pengawasan khusus, dan monitoring secara parsial terhadap penyelenggaraan Pemerintahan Provinsi Papua. Sedangkan tujuan lain yaitu untuk menguji dan menganalisis pengaruh pengawasan rutin, pengawasan khusus, dan monitoring secara simultan terhadap penyelenggaraan Pemerintahan Provinsi Papua serta untuk menguji dan menganalisis faktor yang paling dominan berpengaruh terhadap penyelenggaraan Pemerintahan Provinsi Papua.

\section{METODE PENELITIAN}

Penelitian ini menggunakan pendekatan deskriptif kuantitatif. Lokasi penelitian dilaksanakan di Inspektorat Provinsi Papua. Lokasi penelitian ini dipilih berdasarkan pendekatan ketersediaan data yang dibutuhkan dalam penelitian. Populasi dan Sampel Populasi dalam penelitian adalah seluruh jumlah pegawai pada Kantor Inspektorat Provinsi Papua yang berjumlah 79 orang dan teknik pengumpulan sampel menggunakan sampel acak sederhana (simple random sampling). Sampel penelitian adalah sebanyak 39 orang pegawai pada Kantor Inspektorat Provinsi Papua. Jenis data dalam penelitian ini adalah Data Kualitatif Data Kuantitatif Sumber. Data Sumber data yaitu Data Primer Data Sekunder. Teknik Pengumpulan Data menggunakan kuisioner, Kuesioner (angket), Observasi Wawancara Dokumentasi Data 
Kepustakaan. Teknik analisis data menggunakan Regressi Linear Berganda dengan SPSS.

Definisi Operasional Pengawasan rutin adalah pengawasan yang dilaksanakan oleh Inspektorat Provinsi Papua secara rutin terhadap penyelenggaraan Pemerintahan Provinsi Papua seperti Ketaatan Dalam Mengelola Anggaran Rutin, Kedisiplinan Aparatur terhadap Atasan dan Peratuan dan Pengelolaan Aset Kantor. Pengawasan khusus yaitu pengawasan yang dilakukan oleh Inspektorat Provinsi Papua secara khusus terhadap penyelenggaraan Pemerintahan Provinsi Papua yang meliputi kelengkapan administrasi dan realisasi pengeluaran di lapangan.

Monitoring yaitu pengendalian yang dilakukan oleh Inspektorat Provinsi Papua yang meliputi aspek tindak lanjut hasil pengawasan rutin dan khusus serta perbaikan oleh instansi terkait (obejk pemeriksaan).

\section{HASIL PENELITIAN DAN PEMBAHASAN}

\section{Uji Validitas}

1. Variabel Pengawasan Rutin $\left(\mathrm{X}_{1}\right)$

Tabel 1. Hasil Validitas Variabel Pengawasan Rutin $\left(X_{1}\right)$

\begin{tabular}{|l|l|l|l|}
\hline Pernyataan & $\begin{array}{l}\text { Nilai } \\
\mathrm{R}\end{array}$ & $\begin{array}{l}\text { Nilai } \\
\text { Sig }\end{array}$ & Ket \\
\hline $\mathrm{X}_{1.1}$ & 0,685 & 0,000 & Valid \\
\hline $\mathrm{X}_{1.2}$ & 0,804 & 0,000 & Valid \\
\hline $\mathrm{X}_{1.3}$ & 0,804 & 0,000 & Valid \\
\hline $\mathrm{X}_{1.4}$ & 0,899 & 0,000 & Valid \\
\hline $\mathrm{X}_{1.5}$ & 0,861 & 0,000 & Valid \\
\hline
\end{tabular}

Sumber : Data Diolah 2019

Berdasarkan tabel diatas dapat diketahui bahwa seluruh pernyataan memiliki nilai sig lebih kecil dari 0,05 sehingga dapat disimpulkan bahwa seluruh pernyataan pada variabel pengawasan rutin adalah valid. 
2. Variabel Pengawasan Khusus $\left(\mathrm{X}_{2}\right)$

Tabel 2. Hasil Validitas Variabel Pengawasan Khusus $\left(\mathrm{X}_{2}\right)$

\begin{tabular}{|c|c|c|c|}
\hline Pernyataan & $\begin{array}{l}\text { Nilai } \\
\mathrm{R}\end{array}$ & $\begin{array}{l}\text { Nilai } \\
\text { Siq }\end{array}$ & Ket \\
\hline $\mathrm{X}_{2.1}$ & $\mid 0,895$ & 0,000 & Valid \\
\hline $\mathrm{X}_{2.2}$ & 0,880 & 0,000 & Valid \\
\hline $\mathrm{X}_{2.3}$ & 0,856 & 0,000 & Valid \\
\hline$X_{2.4}$ & 0,915 & 0,000 & Valid \\
\hline $\mathrm{X}_{2.5}$ & 0,822 & 0,000 & Valid \\
\hline
\end{tabular}

Sumber : Data Diolah 2019

Berdasarkan tabel diatas dapat diketahui bahwa seluruh pernyataan memiliki nilai sig lebih kecil dari 0,05 sehingga dapat disimpulkan bahwa seluruh pernyataan pada variabel pengawasan khusus adalah valid.

3. Variabel Monitoring $\left(X_{3}\right)$

Tabel 3. Hasil Validitas Variabel Monitoring $\left(\mathrm{X}_{3}\right)$

\begin{tabular}{|l|l|l|l|}
\hline Pernyataan & $\begin{array}{l}\text { Nilai } \\
\mathrm{R}\end{array}$ & $\begin{array}{l}\text { Nilai } \\
\text { Sig }\end{array}$ & Ket \\
\hline $\mathrm{X}_{3} .1$ & 0,890 & 0,000 & Valid \\
\hline $\mathrm{X}_{3.2}$ & 0,858 & 0,000 & Valid \\
\hline $\mathrm{X}_{3.3} .3$ & 0,000 & Valid \\
\hline $\mathrm{X}_{3.4}$ & 0,901 & 0,000 & Valid \\
\hline $\mathrm{X}_{3.5}$ & 0,818 & 0,000 & Valid \\
\hline
\end{tabular}

Sumber : Data Diolah 2019

Berdasarkan tabel diatas dapat diketahui bahwa seluruh pernyataan memiliki nilai sig lebih kecil dari 0,05 sehingga dapat disimpulkan bahwa seluruh pernyataan pada variabel monitoring adalah valid.

4. Variabel Sistem Penyelenggaraan Pemerintahan $(\mathrm{Y})$

Tabel 4. Hasil Validitas Variabel Penyelenggaraan Pemerintahan ( $Y$ )

\begin{tabular}{|l|l|l|l|}
\hline Pernyataan & $\begin{array}{l}\text { Nilai } \\
\text { R }\end{array}$ & $\begin{array}{l}\text { Nilai } \\
\text { Sig }\end{array}$ & Ket \\
\hline Y.1 & 0,879 & 0,000 & Valid \\
\hline Y.2 & 0,911 & 0,000 & Valid \\
\hline Y.3 & 0,906 & 0,000 & Valid \\
\hline Y.4 & 0,950 & 0,000 & Valid \\
\hline Y.5 & 0,911 & 0,000 & Valid \\
\hline
\end{tabular}

Sumber : Data Diolah 2019 
Berdasarkan tabel diatas dapat diketahui bahwa seluruh pernyataan memiliki nilai sig lebih kecil dari 0,05 sehingga dapat disimpulkan bahwa seluruh pernyataan pada variabel penyelenggaraan pemerintahan adalah valid.

\section{Uji Reliabilitas}

Tabel 5. Hasil Uji Reliabilitas

\begin{tabular}{|c|c|c|c|}
\hline Variabel & $\begin{array}{l}\text { Nilai } \\
\text { Cronbach Alpha }\end{array}$ & Standar & Keterangan \\
\hline Pengawasan Rutin $\left(\mathrm{X}_{1}\right)$ & 0,809 & \multirow{4}{*}{0,60} & Reliabel \\
\hline Pengawasan Khusus $\left(\mathrm{X}_{2}\right)$ & 0,821 & & Reliabel \\
\hline Monitoring $\left(X_{3}\right)$ & 0,819 & & Reliabel \\
\hline Penyelenggaraan Pemerintahan $(\mathrm{Y})$ & 0,828 & & Reliabel \\
\hline
\end{tabular}

Sumber : Data Diolah 2019

Berdasarkan tabel diatas dapat diketahui seluruh variabel memiliki nilai Cronbach Alpha lebih besar dari 0,60, hal ini berarti bahwa seluruh variabel dalam penelitian ini reliabel (handal).

\section{Uji Normalitas}

Gambar 2. Hasil Uji Normalitas

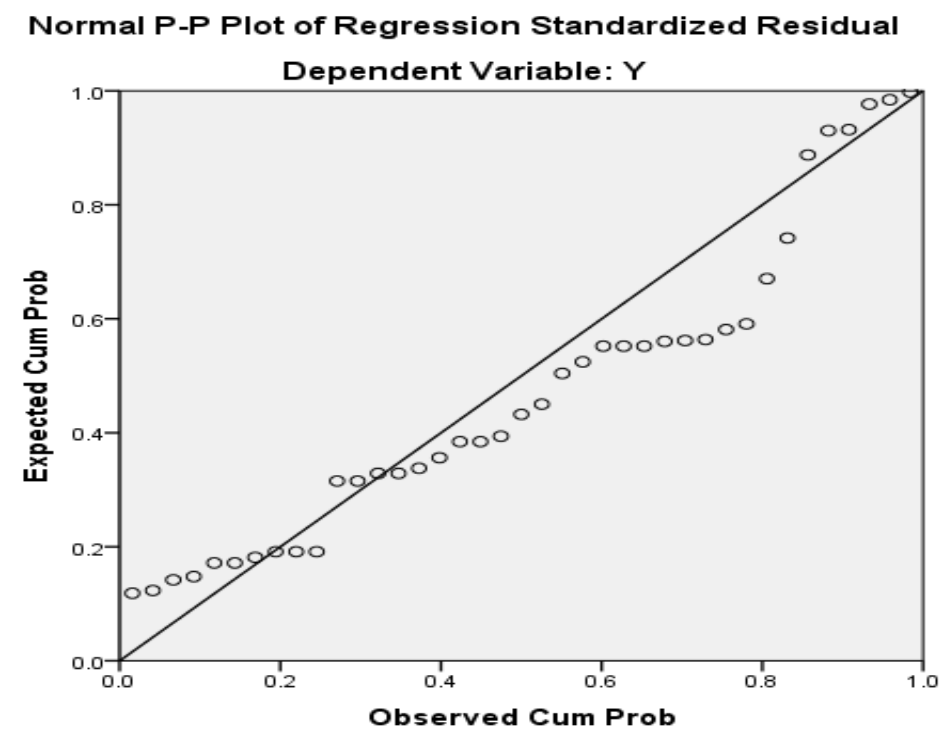

Berdasarkan normal probability plot diatas, maka data penelitian ini dapat dikatakan telah memenuhi kaidah normalitas karena terlihat bahwa data menyebar mengikuti garis diagonal, penyebarannya secara acak, dan tidak membentuk pola tertentu. 


\section{Uji Heterokedastisitas}

Gambar 3. Hasil Uji Heterokedastisitas

Scatterplot

Dependent Variable: $Y$

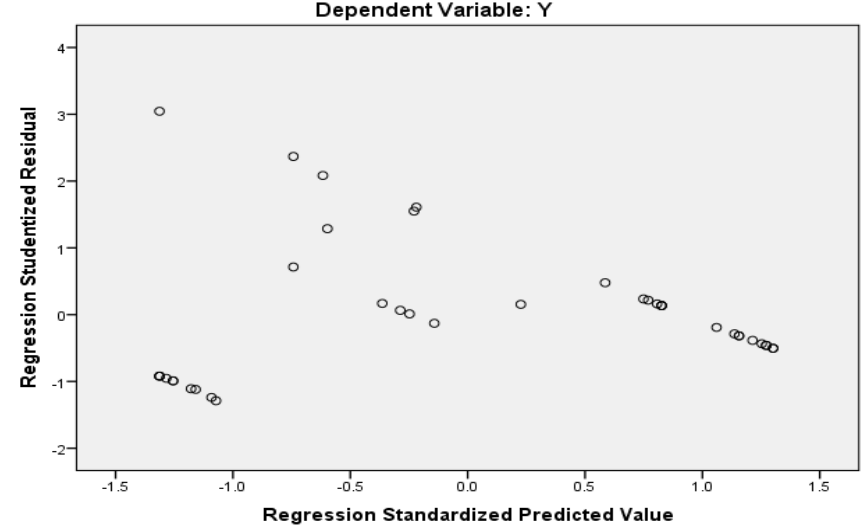

Berdasarkan gambar di atas dapat dijelaskan bahwa titik-titik menyebar diatas dan dibawah angka 0 pada sumbu $\mathrm{Y}$ sehingga dapat disimpulkan bahwa uji tersebut tidak terjadi problem heterokedastisitas.

\section{Uji Multikolinieritas}

Tabel 6. Hasil Pengujian Multikolinieritas

\begin{tabular}{|l|l|l|l|}
\hline \multirow{2}{*}{ Variabel } & \multicolumn{2}{|l|}{ Collinearity Statistics } & \multirow{2}{*}{ Keterangan } \\
\cline { 2 - 3 } & Tolerance & VIF & \\
\hline Pengawasan Rutin $\left(\mathrm{X}_{1}\right)$ & 0,787 & 1,270 & Bebas Multikolinieritas \\
\hline Pengawasan Khusus $\left(\mathrm{X}_{2}\right)$ & 0,639 & 0,693 & Bebas Multikolinieritas \\
\hline Monitoring $\left(\mathrm{X}_{3}\right)$ & 0,856 & 0,856 & Bebas Multikolinieritas \\
\hline
\end{tabular}

Sumber : Data Diolah 2019

Berdasakan tabel diatas hasil pengujian multikolinieritas menunjukkan bahwa nilai tolerance mendekati 1 dan nilai VIP berada dibawah 10 yang berarti tidak terjadi multikolinieritas antar variabel independen dalam penelitian ini. 


\section{Uji Regresi Berganda}

Tabel 7. Hasil Analisis Regresi Berganda

\section{Coefficients $^{a}$}

\begin{tabular}{|c|c|c|c|c|c|}
\hline \multirow[b]{2}{*}{ Model } & \multicolumn{2}{|c|}{$\begin{array}{l}\text { Unstandardized } \\
\text { Coefficients }\end{array}$} & \multirow{2}{*}{\begin{tabular}{|l}
$\begin{array}{l}\text { Standardized } \\
\text { Coefficients }\end{array}$ \\
Beta \\
\end{tabular}} & \multirow[b]{2}{*}{$t$} & \multirow[b]{2}{*}{ Sig. } \\
\hline & $B$ & Std. Error & & & \\
\hline 1 (Constant) & 3.246 & 3.127 & & 1.038 & .306 \\
\hline $\mathrm{X} 1$ & .813 & .119 & .776 & 6.815 & .000 \\
\hline $\mathrm{X} 2$ & .033 & .119 & .033 & .274 & .785 \\
\hline X3 & .050 & .107 & .050 & .462 & .647 \\
\hline
\end{tabular}

a. Dependent Variable: $Y$

Sumber : Data Primer Diolah 2019

Berdasarkan tabel diatas menunjukkan persamaan regresi adalah sebagai berikut :

$$
Y=3,246+0,813 X_{1}+0,033 X_{2}+0,050 X_{3}+e
$$

Dari persamaan regresi tersebut dapat dijelaskan bahwa pengawasan rutin, pengawasan khusus, dan monitoring berpengaruh positif terhadap penyelenggaraan pemerintahan Provinsi Papua.

Nilai konstanta 3,246 menunjukkan bahwa apabila variabel pengawasan rutin, pengawasan khusus, dan monitoring dalam kondisi tetap atau konstan, maka penyelenggaraan pemerintahan sebesar 3,246 satuan, yang berarti bahwa tanpa adanya variabel bebas yaitu pengawasan rutin, pengawasan khusus, dan monitoring, maka penyelenggaraan pemerintahan akan tetap sebesar $3,246$.

Nilai koefisien regresi variabel pengawasan rutin terhadap penyelenggaraan pemerintahan sebesar 0,813 dengan tanda positif artinya apabila indikator-indikator pengawasan rutin meningkat, maka akan meningkatkan penyelenggaraan pemerintahan, jika variabel lainnya dianggap konstan/tetap.

Nilai koefisien regresi variabel pengawasan khusus terhadap penyelenggaraan pemerintahan sebesar 0,033 dengan tanda positif artinya apabila indikator-indikator pengawasan 
khusus meningkat, maka akan meningkatkan penyelenggaraan pemerintahan, jika variabel lainnya dianggap konstan/tetap.

Nilai koefisien regresi variabel monitoring terhadap penyelenggaraan pemerintahan sebesar 0,050 dengan tanda positif artinya apabila indikator-indikator monitoring meningkat, maka akan meningkatkan penyelenggaraan pemerintahan, jika variabel lainnya dianggap konstan/tetap.

\section{Uji T}

a. Pengaruh Pengawasan Rutin terhadap Penyelenggaraan Pemerintahan Provinsi Papua Berdasarkan hasil pengolahan data pada tabel 14 diatas diperoleh nilai thitung sebesar 6,815 > $t_{\text {tabel }}$ Sebesar 1,689 dan nilai signifikansi atau probabilitas sebesar $0,000<$ taraf signifikansi 5\% atau 0,05 artinya pengawasan rutin berpengaruh terhadap penyelenggaraan pemerintahan Provinsi Papua.

b. Pengaruh Pengawasan Khusus terhadap Penyelenggaraan Pemerintahan Provinsi Papua Berdasarkan hasil pengolahan data pada tabel 14 diatas diperoleh nilai thitung sebesar 0,274< $t_{\text {tabel }}$ Sebesar 1,689 dan nilai signifikansi atau probabilitas sebesar 0,785 > taraf signifikansi 5\% atau 0,05 artinya pengawasan khusus tidak berpengaruh terhadap penyelenggaraan pemerintahan Provinsi Papua.

c. Pengaruh Monitoring terhadap Penyelenggaraan Pemerintahan Provinsi Papua Berdasarkan hasil pengolahan data pada tabel 14 diatas diperoleh nilai thitung sebesar 0,462< $t_{\text {tabel }}$ Sebesar 1,689 dan nilai signifikansi atau probabilitas sebesar 0,647 > taraf signifikansi 5\% atau 0,05 artinya monitoring tidak berpengaruh terhadap penyelenggaraan pemerintahan Provinsi Papua.

Berdasarkan hasil uji t diatas menunjukkan bahwa variabel yang paling dominan berpengaruh terhadap penyelenggaraan pemerintahan Provinsi Papua adalah variabel pengawasan rutin $\left(\mathrm{X}_{1}\right)$ 
karena memiliki nilai thitung yang lebih besar yaitu 6,815 dengan nilai signifikansi sebesar 0,000 dibandingkan dengan nilai thitung variabel pengawasan khusus $(0,274)$ dan monitoring $(0,462)$.

Uji F

ANOVA $^{\mathrm{a}}$

Tabel 8. Uji Simultan (Uji F)

\begin{tabular}{|ll|l|l|l|l|l|}
\hline Model & & $\begin{array}{l}\text { Sum } \\
\text { Squares }\end{array}$ & off & Mean Square & F & Sig. \\
\hline 1 & Regression & 111.559 & 3 & 37.186 & 21.034 & $.000^{\mathrm{b}}$ \\
& Residual & 61.877 & 35 & 1.768 & & \\
& Total & 173.436 & 38 & & & \\
\hline
\end{tabular}

a. Dependent Variable: $Y$

b. Predictors: (Constant), X3, X1, X2

Sumber : Data Diolah 2019

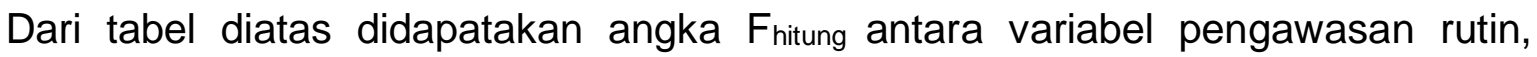
pengawasan khusus, dan monitoring secara simultan yaitu sebesar 21,034 lebih besar dibandingkan dengan nilai $F_{\text {tabel }}$ yaitu 2,87 dan nilai probabilitas sebesar 0,000 lebih kecil dibandingkan dengan taraf signifikan $5 \%$ atau 0,05 . Sehingga dapat disimpulkan bahwa ada pengaruh positif dan signifikan antara pengawasan rutin, pengawasan khusus, dan monitoring terhadap penyelenggaraan pemerintahan Provinsi Papua secara simultan atau bersama-sama.

\section{PEMBAHASAN}

Pengaruh pengawasan rutin, pengawasan khusus, dan monitoring secara parsial terhadap penyelenggaraan Pemerintahan Provinsi Papua.

a. Pengaruh pengawasan rutin terhadap penyelenggaraan Pemerintahan Provinsi Papua. 
Pengawasan rutin merupakan pengawasan yang ditujukan dalam objek kinerja Instansi Pemerintahan yang meliputi pengelolaan aspek keuangan, kepegawaian, dan perlengakapan (SK Mendagri No. 06 Tahun 2003)

Hasil tanggapan responden berdasarkan rekapitulasi kuisioner menunjukkan bahwa rata-rata responden setuju dengan pertanyaan kuisioner yang diberikan yang menyangkut tentang pengawasan rutin yang dilakukan oleh Inspektorat Provinsi Papua yaitu dengan nilai rata-rata adalah 4,50. Hasil pengolahan data menunjukkan bahwa pengawasan rutin berpengaruh signifikan terhadap penyelenggaraan pemerintahan Provinsi Papua. Sejalan dengan penelitian terdahulu yang dilakukan oleh Wandi Harmawan (2012) dengan hasil penelitian menunjukkan bahwa pengawasan rutin yang dilakukan oleh inspektorat sudah berjalan dengan baik.

Selain hasil pengolahan data yang dilakukan tentang pelaksanaan pengawasan rutin yang dilakukan oleh Kantor Inspektorat Provinsi Papua, adapun hasil wawancara dengan kepala Inspektorat tentang pengawasan rutin adalah sebagai berikut :

"Pada kantor ini semua pegawai sudah menjalankan tugas dan tanggung jawab mereka masing-masing. Para auditor selalu melakukan pengawasn rutin ke instansi-intansi pemerintah. Auditor juga biasanya melakukan pengawasan ke instansi-intansi pemerintah sesuai dengan kasus pengaduan sehingga pengawasan rutin yang dilakukan oleh auditor sudah berjalan dengan baik dan sesuai dengan prosedur yang ada".(Inspektur) 
Pegawasan rutin yang dilakukan oleh Kantor Inspektorat Provinsi Papua terhadap penyelenggaraan Pemerintahan Provinsi Papua bertujuan agar supaya instansi-instansi pemerintah dapat mengelola keuangan, kepegawaian, dan kelengkapan lainnya sehingga instansi-instansi pemerintah Papua dapat berjalan dengan baik. Meskipun terkadang pengawasan rutin tidak berjalan dengan baik atau tidak sesuai dengan waktu yang telah ditentukan, akan tetapi pengawasan rutin yang dilakukan oleh Kantor Inspektorat Provinsi Papua sudah dilakukan sesuai dengan prosedur yang berlaku. Tujuan dari pengawasan rutin yaitu

a. Menghentikan atau menidakdan kesalahan, penyelewengan, pemborosan dan hambatan

b. Mencegah terulang kembalinya kesalahan penyelewengan, pemborosan, dan hambatan

c. Meningkatkan kelancaran instansi pemerintah

d. Meningkatkan kinerja instansi pemerintah

b. Pengaruh pengawasan khusus terhadap penyelenggaraan Pemerintahan Provinsi Papua.

Pengawasan rutin merupakan pengawasan yang dilakukan terhadap suatu kegiatan instansi pemerintah yang diduga terjadi kemungkinan adanya kesalahan administrasi dan adanya kemungkinan terjadi tindak pidana korupsi berdasarkan laporan masyarakat dan inisiatif Inspektorat (SK Mendagri No. 06 Tahun 2003)

Hasil tanggapan responden berdasarkan rekapitulasi kuisioner menunjukkan bahwa rata-rata responden setuju dengan pertanyaan kuisioner yang diberikan yang menyangkut tentang pengawasan khusus yang dilakukan oleh Inspektorat 
Provinsi Papua yaitu dengan nilai rata-rata adalah 4,58. Hasil pengolahan data yang dilakukan menunjukkan bahwa pengawasan khusus tidak berpengaruh terhadap penyelenggaraan pemerintahan Provinsi Papua. Berbanding terbalik dengan hasil penelitian terdahulu yang dilakukan oleh Adi Nugraha (2015) dengan hasil penelitian menunjukkan bahwa pengawasan khusus berpengaruh signifikan terhadap penyelenggaraan pemerintahan daerah.

Selain hasil pengolahan data yang dilakukan tentang pelaksanaan pengawasan khusus yang dilakukan oleh Kantor Inspektorat Provinsi Papua, adapun hasil wawancara dengan kepala Inspektorat tentang pengawasan khusus adalah sebagai berikut :

"Pengawasan khusus yang dilakukan auditor biasanya kebanyak berdasarkan laporan masyarakat atau memang instansi terkait lagi bermasalah dalam tertib administrasi. Pengawasan khusus selalu dilakukan oleh auditor akan tetapi karena jumlah auditor yang masih kurang dan tidak sebanding dengan objek pemeriksaan sehingga pengawasan khusus yang dilakukan belum maksimal”.(Inspektur).

Berdasarkan hasil wawancara menunjukkan bahwa pengawasan khusus belum maksimal dilakukan karena disebabkan oleh jumlah auditor yang belum memadai dalam melaksanakan tugas Kantor Inspektora Provinsi Papua. Hal ini berarti belum tercapainya sepenuhnya sasaran pengawasan khusus yaitu
a. Mengarahkan atau merekomendasikan perbaikan
b. Menyarankan agar ditekan adanya pemborosan
c. Mengoprimalkan pekerjaan untuk mencapai sasaran rencana 


\section{c. Pengaruh monitoring terhadap penyelenggaraan Pemerintahan Provinsi} Papua.

Monitoring yaitu seiring dengan pengawasan yang dilakukan sepanjang suatu kegiatan atau proyek sedang berlangsung dan bertujuan kegiatan tersebut, sesuai fungsi, dan sasaran (SK Mendagri No. 06 Tahun 2003).

Hasil tanggapan responden berdasarkan rekapitulasi kuisioner menunjukkan bahwa rata-rata responden setuju dengan pertanyaan kuisioner yang diberikan yang menyangkut tentang monitoring yang dilakukan oleh Inspektorat Provinsi Papua yaitu dengan nilai rata-rata adalah 4,53. Hasil pengolahan data yang dilakukan menunjukkan bahwa monitoring tidak berpengaruh terhadap penyelenggaraan pemerintahan Provinsi Papua. Sejalan dengan penelitian terdahulu yang dilakukan oleh Hermin Arifianti (2013) yang menunjukkan bahwa monitoring tidak mempunyai pengaruh terhadap kinerja penyelenggaraan pemerintahan.

Selain hasil pengolahan data yang dilakukan tentang pelaksanaan monitoring yang dilakukan oleh Kantor Inspektorat Provinsi Papua, adapun hasil wawancara dengan kepala Inspektorat tentang monitoring adalah sebagai berikut :

"Kegiatan monitoring yang dilakukan para auditor sudah sesuai dengan sistem dan prosedur yang ada. Akan tetapi akan tetapi sistem dan prosedur kerja pengawasan khususnya monitoring belum sepenuhnya dilaksanakan. Hal ini disebabkan oleh jumlah auditor yang masih kurang. Pegawai yang mempunyai sertifikasi auditor sebanyak 33 orang. Dari 33 orang tersebut hanya 13 orang saja yang aktif karena 4 orang dibebaskan sementara sebagai auditor karena 
menduduki jabatan structural dan 16 orang sudah memiliki sertifikasi tetapi belum diangkat sebagai auditor. Hal ini yang salah satu menjadi kendala kurang maksimalnya monitoring yang dilakukan ke instansi pemerintah".(Inspektur).

Berdasarkan hasil wawancara menunjukkan bahwa monitoring belum maksimal dilakukan karena disebabkan oleh jumlah auditor yang masih kurang dalam melaksanakan monitoring ke instansi-instansi pemerintah, aparat pengawas pada Kantor Inspektorat Provinsi Papua kurang aktif dalam melakukan monitoring terhadap instansi pemerintah, dan kompetensi pejabat fungsional auiditor yang belum memadai sehingga berdampak kepada kegiatan monitoring belum dijalankan dengan efektif sehingga kegiatan monitoring belum berjalan dengan maksimal. Kurang efektifnya kegiatan monitoring yang dilakukan berarti tujuan dilakukannya monitoring belum tercapai. Adapun tujuan dari kegiatan monitoring yaitu :

1. Memastikan suatu proses dilakukan sesuai prosedur yang berlaku. Sehingga, proses berjalan sesuai jalur yang disediakan (on the track).

2. Menyediakan probabilitas tinggi akan keakuratan data bagi pelaku monitoring.

3. Mengidentifikasi hasil yang tidak diinginkan pada suatu proses dengan cepat (tanpa menunggu proses selesai).

4. Menumbuh kembangkan motivasi dan kebiasaan positif pekerja.

Pengaruh pengawasan rutin, pengawasan khusus, dan monitoring secara simultan terhadap penyelenggaraan Pemerintahan Provinsi Papua.

Penyelenggaraan urusan pemerintahan terdiri dari sentralisasi dan desentralisasi. Sentralisasi adalah memusatkan seluruh wewenang atas segala urusan yang menyangkut pemerintahan kepada tingkat pusat. Sentralisasi banyak digunakan pada 
pemerintahan lama di Indonesia sebelum adanya otonomi daerah. Bahkan pada zaman kerajaan, pemerintahan kolonial, maupun di zaman kemerdekaan. Istilah sentralisasi sendiri sering digunakan dalam kaitannya dengan kontrol terhadap kekuasaan dan lokasi yang berpusat pada satu titik. Sedangkan desentralisasi adalah kebalikan dari sentralisasi. Menurut Litvack \& Seddon Wasistiono dan Wiyoso (2009:7) desentralisasi adalah transfer kewenangan dan tanggung jawab berkaitan dengan fungsi-fungsi publik dari pemerintah pusat kepada organisasi pemerintah yang ada di bawahnya, atau organisasi semi bebas, ataupun sektor privat. Menurut Rasyid Yudoyono (2003:20) desentralisasi adalah pelimpahan wewenang dari tingkat atas organisasi kepada tingkat bawahnya secara hirarkis. Sedangkan Mahfud MD Tangkilisan (2005) menyatakan bahwa desentralisasi merupakan penyerahan wewenang dari pemerintah pusat kepada pemerintah daerah untuk mengatur dan mengurus daerah, mulai dari kebijakan, perencanaan, sampai pada implementasi dan pembiayaan dalam rangka demokrasi.

Hasil tanggapan responden berdasarkan rekapitulasi kuisioner menunjukkan bahwa rata-rata responden setuju dengan pertanyaan kuisioner yang diberikan yang menyangkut tentang penyelenggaraan pemerintahan yaitu dengan nilai rata-rata adalah 4,68 dan Hasil penelitian dan pengolahan data yang dilakukan menunjukkan bahwa angka Fhitung antara variabel pengawasan rutin, pengawasan khusus, dan monitoring secara simultan yaitu sebesar 21,034 lebih besar dibandingkan dengan nilai $F_{\text {tabel }}$ yaitu 2,87 dan nilai probabilitas sebesar 0,000 lebih kecil dibandingkan dengan taraf signifikan $5 \%$ atau 0,05 . Sehingga dapat disimpulkan bahwa ada pengaruh positif dan signifikan antara pengawasan rutin, pengawasan khusus, dan monitoring terhadap penyelenggaraan pemerintahan Provinsi Papua secara simultan atau bersama-sama. 
Sejalan dengan penelitian terdahulu yang dilakukan oleh Yakobus (2018) dengan hasil penelitian menjukkan bahwa implementasi pengawasan yang terdiri dari beberapa faktor pengawasan yang mempunyai pengaruh terhadap peningkatkan efektifitas penyelenggaraan pemerintahan daerah. Adapun hasil wawancara dengan kepala Inspektorat tentang penyelenggaraan pemerintahan Provinsi Papua adalah sebagai berikut :

"Pemerintahan Provinsi Papua sekarang sudah berjalan dengan baik dan tertib administrasi, meskipun terdapat beberapa instansi yang masih melakukan kesalahan dalam hal administrasi dari beberapa aspek akan tetapi masih biss diperbaiki dan juga jika instansi sudah sangat parah dalam melakukan kesalahan, maka akan diproses lebih lanjut sesuai dengan aturan hokum yang berlaku".(Inspektur).

Berdasarkan hasil wawancara menunjukkan bahwa penyelenggaraan Pemerintahan Provinsi Papua sudah berjalan dengan baik. Hal ini berarti seluruh wewenang atas segala urusan yang menyangkut pemerintahan sudah berjalan sesuai dengan prosedur dan juga kewenangan dan tanggungjawab yang berkaitan dengan fungsi-fungsi public dari pemerintah pusat kepada organisasi pemerintah yang ada dibawahnya, atau organisasi semi bebas, ataupun sektor privat sudah berjalan dengan baik.

Faktor yang lebih dominan berpengaruh terhadap penyelenggaraan Pemerintahan Provinsi Papua.

Pemerintahan sebagai kegiatan yang berkenaan dengan fungsi negara, maka perlu dikemukakan pengertian pemerintahan dalam arti luas dan sempit. Pemerintahan dalam 
arti luas berarti seluruh fungsi negara, seperti 35Legislative, eksekutif, dan yudikatif. Sedangkan pemerintahan dalam arti sempit meliputi fungsi eksekutif saja. Demikian pula dengan pengertian pemerintah dalam arti luas yang berarti seluruh aparat yang melaksanakan fungsi fungsi negara, sedangkan pemerintah dalam arti sempit menyangkut aparat eksekutif, yaitu kepala pemerintahan dan kabinetnya (Surbakti, 1999:169).

Berdasarkan hasil penelitian dan pengolahan data yang dilakukan menunjukkan bahwa variabel yang paling dominan berpengaruh terhadap penyelenggaraan pemerintahan Provinsi Papua adalah variabel pengawasan rutin $\left(\mathrm{X}_{1}\right)$ karena memiliki nilai thitung yang lebih besar yaitu 6,815 dengan nilai signifikansi sebesar 0,000 dibandingkan dengan nilai thitung variabel pengawasan khusus $(0,274)$ dan monitoring $(0,462)$.

Dalam pelaksanaan fungsi pengawasan Inspektorat masih terdapat beberapa kendala diantaranya yaitu

1. Sistem dan prosedur kerja pengawasan yang belum dilaksanakan sepenuhnya.

2. Jumlah pejabat fungsional auditor/P2UPD yang masih kurang dan tidak sebanding dengan objek pemeriksaan yang menjadi beban tugas pengawasan.

3. Kompetensi pejabat fungsional auditor/P2UPD yang belum memadai.

4. Kebutuhan jabatan fungsional belum sepenuhnya terpenuhi sesuai analisis kebutuhan jabatan fungsional pengawasan internal.

Dari beberapa kendala tersebut diatas, Inspektorat Provinsi Papua sudah mengupayakan kebijakan untuk mengatasi kendala yang dihadapi seperti peningkatan sistem dan prosedur kerja pegawas dengan mengikutkan beberapa pegawai dalam 
kegiatan-kegiatan atau pelatihan yang berhubungan dengan prosedur kerja pengawas, permintaan tenaga auditor dan untuk tenaga fungsional pengawasan internal, dan peningkatan kompetensi pejabat fungsinal auditor/P2UPD.

\section{KESIMPULAN}

Variabel pengawasan rutin secara parsial mempunyai pengaruh yang signifikan terhadap penyelenggaraan pemerintahan Provinsi Papua. Sedangkan variabel pengawasan khusus dan monitoring secara parsial tidak mempunyai pengaruh yang signifikan terhadap penyelenggaraan pemerintahan Provinsi Papua. Hal ini menunjukkan bahwa pengawasan khusus dan monitoing belum dilaksanakan secara maksimal karena disebabkan beberapa faktor diantaranya jumlah auditor yang masih kurang dan tidak sebanding dengan objek pemeriksaan.

Variabel pengawasan rutin, pengawasan khusus, dan monitoring secara simultan mempunyai pengaruh yang signifikan terhadap penyelenggaraan pemerintahan Provinsi Papua. Hal ini menunjukkan bahwa penyelenggaraan pemerintahan Provinsi Papua sudah berjalan dengan baik.

Variabel pengawasan rutin merpakan faktor yang paling dominan mempunyai pengaruh terhadap penyelenggaraan pemerintahan Provinsi Papua. Hal ini menunjukkan pengawasan rutin yang dilakukan oleh para auditor sudah berjalan dengan baik dan sesuai dengan prosedur yang berlaku.

\section{DAFTAR PUSTAKA}

Adi Nugraha, B. (2015). Pengaruh Pemeriksaan Dan Pengawasan Keuangan Daerah Terhadap Kinerja Penyelenggaraan Pemerintah Daerah (Studi Empiris Pada Pemerintah Daerah Kabupaten/Kota Di Sumatera). Universitas Muhammadiyah Surakarta. 
Arifianti, H. (n.d.). Payamta, dan Sutaryo. 2013. Pengaruh Pemeriksaan Dan Pengawasan Keuangan Daerah Terhadap Kinerja Penyelenggaraan Pemerintahan Daerah (Studi Empiris Pada Pemerintah Kabupaten/Kota Di Indonesia). Simposium Nasional Akuntansi XVI. Manado.

Harmawan, I., Kabir, C. S., Habib, S. M., Kennedy, J., Henson, J., \& Minhas, H. N. (2012). Integrating mini-DST-derived permeability with other sources: A case study. SPE Reservoir Evaluation \& Engineering, 15(03), 361-369.

Litvack, J. I., \& Seddon, J. (1999). Decentralization briefing notes. World Bank Institute Washington, DC.

Murafer, Y. (2018). Peningkatan Pengawasan Partisipatif Oleh Panwaslu Kota Jayapura Dalam Pemilihan Gubernur Dan Wakil Gubernur Provinsi Papua Tahun 2018 Di Kota Jayapura. JURNAL POLITIK PEMERINTAHAN, 2(2).

Salam, D. S., Syafrudin, A., \& Rasyid, M. R. (2001). Otonomi daerah: dalam perspektif lingkungan, nilai, dan sumber daya. Djambatan.

Siradja, N. G. (2016). Analisis Pelaksanaan Pengawasan Inspektorat Daerah terhadap Kinerja Badan Kepegawaian Daerah Kota Baubau.

Tangkilisan, H. N. S. (2005). Manajemen publik. Grasindo.

Yustisia, T. V. (2015). Undang-Undang No 23 Tahun 2014 tentang Pemerintahan Daerah dan Perubahannya. VisiMedia. 